\title{
Estudos em Asclepiadaceae - XXV. Uma nova espécie de Matelea Aubl.
}

\author{
Jorge Fontella Pereira \\ Pesquisador do Jardim Botânico do Rio de Janeiro (IBAMA) \\ Bolsista do Conselho Nacional de Desenvolvimento \\ Científico e Tecnológico ( $\mathrm{CNPq})$
}

Resumo

Uma nova espécie de Matelea Aubl. (M. matogrossensis) do Estado de Mato Grosso do Sul é descrita.

\section{Abstract}

A new species of Matelea Aubl. (M. matogrossensis) from Mato Grosso do Sul state is described.

\section{Matelea matogrossensis Font. sp. nov. (Fig. 1)}

Planta volubilis. Ramuli pubescentes. Petioli pubescentes, 6-10 mm longi; laminae lanceolatae, basi cordatae vel subcordatae, apice acuminatae, glabrescentes, supra in basi nervi primarii glandulis 2-3 praeditae, $33-50 \mathrm{~mm}$ longae, $6-13 \mathrm{~mm}$ latae. Cymae umbeliformes, alternae, extra-axillares, 6-9 florae; pedunculo pubescente, 3-3,5mm longo; pedicelli pubescentes, tribracteolati, 4,5-6mm longi. Sepala ovata, acuta vel obtusa, extus pilosa, intus glabra, marginibus ciliatis, 1,3-1,5mm longa, $1-1,2 \mathrm{~mm}$ lata, glandulis singulis in axillis. Corolla rotacea, flava, glabra; tubus brevissimus, $0,3-0,4 \mathrm{~mm}$ longus; lobi ovati vel ovato-triangulares, erecti, apice acuti aut obtusi, 2-2,3mm longi, $1,6-1,8 \mathrm{~mm}$ lati. Corona vinosa, $0,6-0,8 \mathrm{~mm}$ alta, segmentis suborbicularibus, basi nonnihil connatis, intus ruga carnosula ornatis. Gynostegium breviter stipitatum altius corona, $0,8-1,0 \mathrm{~mm}$ altum. Retinaculum trullatum vel subtrullatum, 0,133-152 $\mu \mathrm{m}$ longum, 57-76 $\mu \mathrm{m}$ latum in parte mediana; caudiculae horizontales, articulatae, minute reticulatae, 114-133 $\mu$ m longae; pollinia clavata aut subclavata, horizontalia, 238-295 $\mu \mathrm{m}$ longa, 123-152 $\mu$ m lata in parte mediana. Caput gynostegii depressum.

HOLOTYPUS - Brasil: Estado de Mato Grosso do Sul, Municipio de Terenos, Cachoeirão, 13 VIII 1970, leg. G. Hatschbach 24617 et O. Guimarães s/n? (MBM).

Matelea orthosioidi proxime est affinis, sed petalis erectis, corona alta vinacea, pollinis et retinaculo minoribus ab ea differt.

\section{Agradecimentos}

Ao Conselho Nacional de Desenvolvimento Científico e Tecnológico (CNPq) pela bolsa concedida.

Ao Biólogo André Márcio Araujo Amorim pelos desenhos da espécie e ao Dr. Gert Hatschbach, Diretor do Museu Botânico Municipal de Curitiba, pelo empréstimo do material.

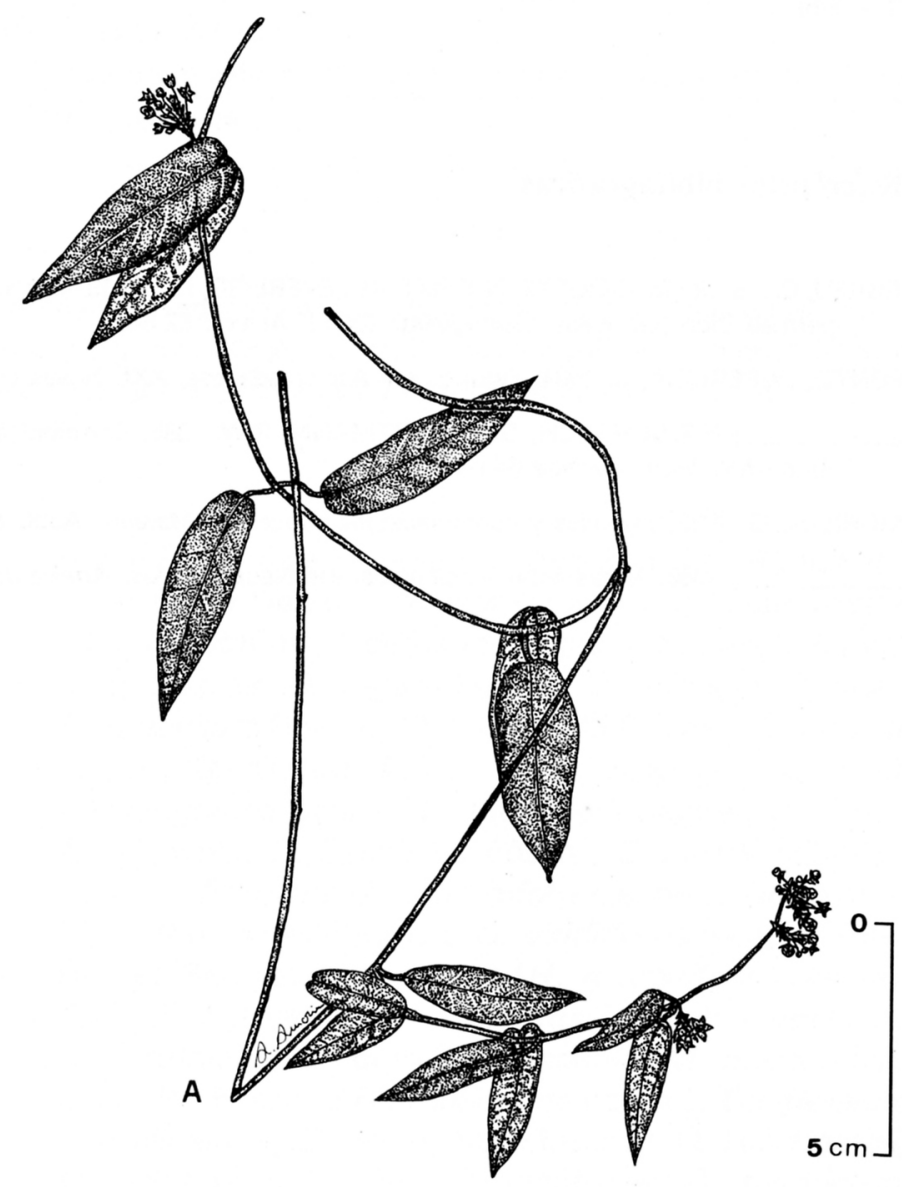

A - Hábito

Recebido em 11/07/89; aceito em 13/10/89 

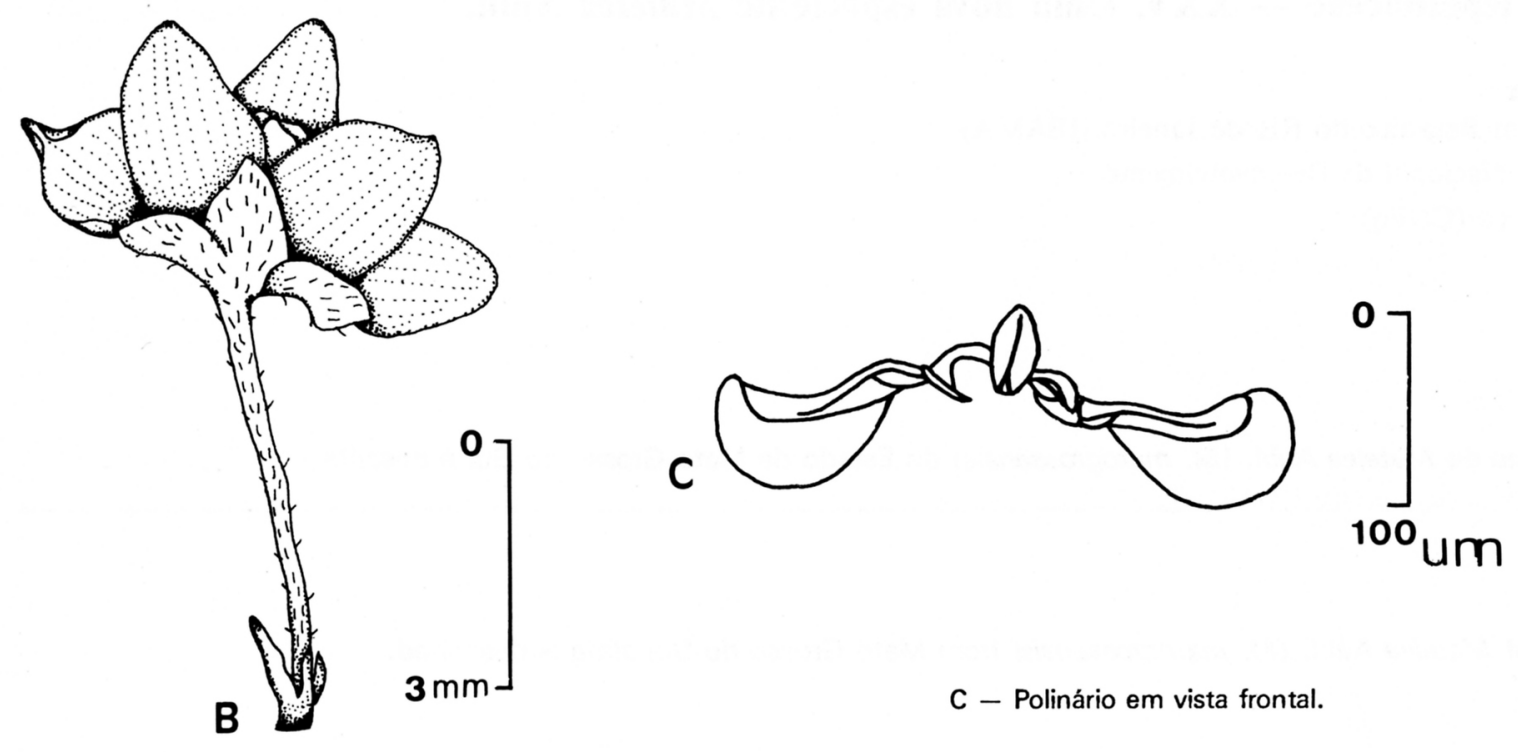

C - Polinário em vista frontal.

B - Flor

\section{Referências bibliográficas}

ABREU, C.L.B. de; MARQUETE, N.F. da S. \& FEVEREIRO, P.C.A. 1974. Asclepiadaceae. In: permae Dicotyledoneae. Rodriguésia 2オ39), Anexo: 52-64.

FONTELLA-PEREIRA, J. 1984. Estudos em Asclepiadaceae, XXI. Novas combinações. Bradea 4(9):55-56.

; HATSCHBACH, G. \& HARTMANN, R.W. 1985. Contribuição ao Estudo das Asclepiadaceae do Paraná, III. Notas preliminares. Bol. Mus. Bot. Mun. Curitiba 64:1-47.

MORILLO, G. 1985. Especies y combinaciones nuevas en Matelea. Aubl. Ernstia 29.1-9, fig. 1.

1986. Notas sobre Asclepiadaceae Neotropicales. Anales Jard. Bot. Madrid 43-11:235-244, 2 fig. 